\title{
Consequences of Health Expenditure among Rural and Urban Households in Oyo State, Nigeria
}

\author{
Olayinka Stephen Ilesanmi (MSc, MPH, FWACP) ${ }^{1,2 *}$, Akindele Oluwapelumi Adebiyi (MPH, \\ FMCPH, PhD) ${ }^{1,2}$, Akinola Ayoola Fatiregun (MSc Epid\& Med Stat, FWACP) ${ }^{3}$, Gbemisola \\ Ishola (MSc, FWACP) $)^{2}$ \\ ${ }^{1}$ Department of Community Medicine, University of Ibadan, Oyo State \\ ${ }^{2}$ Department of Community Medicine, University College Hospital, Ibadan, Oyo State \\ ${ }^{3}$ Ondo State Office, World Health Organisation, Akure, Ondo State
}

*Corresponding Author: Olayinka Stephen Ilesanmi, Department of Community Medicine, University of Ibadan, Oyo State \& Department of Community Medicine, University College Hospital, Ibadan, Oyo State

\begin{abstract}
:
Background: In Nigeria, the financial burden of health care costs is borne almost entirely by the individuals and household members as the health care financing is still mostly from out-of-pocket (OOP) payments. OOP payments has consequences. This study was done to determine the extent and consequences of health expenditure in rural and urban households in Oyo state.

Methods: This study was conducted in urban and rural communities of Oyo State, South-West Nigeria. It was a comparative cross-sectional study. A pre-tested questionnaire was used to collect information on 5,696 household members from 1,434 household representatives selected using multistage sampling method. Information was collected from $714(49.8 \%$ ) and $720(50.2 \%)$ households in the urban and rural Local Government Area (LGA) respectively.
\end{abstract}

Result: Health care was utilised by $1,006(70.2 \%)$ of the 1,434 households studied. Utilization of health care services in urban and rural communities was by 637(89.2\%) and 369(51.3\%) households respectively, $\mathrm{p}<0.001$. The median monthly household cost of health care for urban household was 890(10-17,700) while the rural household had a median cost of $\$ 2,600(50-28,900), \mathrm{p}<0.001$. A higher proportion of urban households 505(79.3\%) had adverse coping mechanism due to health care cost compared to 54(14.6\%) of rural households, $\mathrm{p}<0.001$.

Conclusion: Removal of user fees, especially for primary health services will help the poor to eliminate the burden of health care cost.

Keywords: Wealth-quintiles, Cost, Out of Pocket Expenditure, National Health Insurance Scheme.

Acknowledgement: The authors acknowledge the Medical Officers of Health who contributed to the success of the data collection.

Criteria for inclusion in the authors'/ contributors' list

Concept and design of the study were done by OSI, AOA and AAF. Literature search, data collection and statistical analysis was done by OSI. Manuscript preparation and initial manuscript editing was by GI. Manuscript review and review of intellectual content was by all the authors. OSI and GI will take responsibility for the integrity of the work from inception to published article.

\section{INTRODUCTION}

Health care expenditures often place a burden on the financial sustainability of households particularly in resource-poor settings where effective coverage of health insurance schemes are lacking and out-of -pocket (OOP) expenditure is the common form of health care financing. ${ }^{[1,2]}$ Out-of -pocket health expenses have been shown to have negative impact on health equity, healthcare utilization and may lead to catastrophic spending. ${ }^{[1,3]}$ Catastrophic costs due to healthcare refer to households spending more than a stated percentage threshold of their income (or non-food 
expenditure) on healthcare. ${ }^{[4,5]}$ Health expenditure can also be described as catastrophic if a household's health expenditure exceeds $40 \%$ of income remaining after subsistence needs have been met. $^{[6,7]}$ The World Health Organisation (WHO) estimates that families who spend $40 \%$ or more of their non-food expenditure on health care are likely to be impoverished. ${ }^{[8,9]}$

The impact of out-of-pocket payments for health care is beyond catastrophic expenditure alone. Relatively small expenditures on health can also be financially disastrous for poor households. Many people in need of health care, particularly the poor, may not utilize health services, some may patronise low quality health care, simply because they cannot meet the expense of the direct costs. ${ }^{[6]}$ Therefore, household treatment-seeking patterns may be predicted by the method of financing healthcare ${ }^{[10]}$ With all these implications for household sustainability, there is a persistent interest in the impact of health care spending on the affordability of health care in both rural and urban communities.

Strategies for coping with payments for health care further increase household's susceptibility to impoverishment. ${ }^{[11]}$ Some of these coping strategies for payment of health expenditures include households only being able to manage payments by employing sale of assets, borrowing, and reduction in household consumption, which are all likely to have adverse effects on their wellbeing. ${ }^{[12,13]}$ The overall frequency of using such strategies were found to be more common among the poorest countries and those people with limited health insurance. ${ }^{[14]}$

Household health care expenditure considering all illnesses and other reasons for seeking health care in urban and rural areas of Oyo State are yet to be extensively studied. ${ }^{[15]}$ Most studies in Nigeria $t$ have focused on malaria treatment expenditure alone. ${ }^{[16-18]}$ There is therefore, an urgent need to identify the scale and scope of the consequences of health care expenditure among rural and urban communities in Oyo State Nigeria to act as a catalyst for promoting and informing the development of policy responses to equity in health care delivery such as social insurance.Therefore, this study was done to determine the extent and consequences of health expenditure in rural and urban households in Oyo state.

\section{MeTHODS}

The study was conducted in Ibadan South West (urban) and Ibarapa North (rural) Local Government Areas (LGAs) of Oyo state. Ibadan South West LGA has its administrative headquarter at Oluyole estate with a land mass of 1,335 square kilometres and a population density of 2401 persons per square kilometre. The estimated population is 320,536 , using a growth rate of $3.2 \%$ from 2006 census. Majority of the inhabitants of the LGA fall in the middle and high socio economic class. ${ }^{[19]}$ Ibarapa North LGA has Ayete as its headquarters with a total population was 113,130 in 2010 using a growth rate of $3.2 \%$ from 2006 population census. ${ }^{[20]}$ The Majority of the people are Yorubas and farmers, with others being artisan, traders and few public servants.

The study is a comparative, cross-sectional design. Study population was every member of the households in the selected communities in both rural and urban LGA of Oyo State. Study participants are household who have resided in the selected settlements for at least one year. Where the heads were not available, the spouse or the most informed person in the household aged 18 years and above were interviewed. Households who were enrolled in health insurance scheme and did not make any counterpart payment for health care services received were excluded. The sample size was determined using the formula for comparing two proportions. ${ }^{[21]}$ In both rural and urban LGA, 730 households were visited. A multistage sampling technique was used to select the households.

\subsection{Data Collection}

A semi-structured, pretested and interviewer-administered questionnaire adapted from a standardized questionnaire on Living Standards Measurement for developing countries developed by the World Bank was used. ${ }^{[23]}$ The questionnaire obtained information on socio-demographic data, household 
health services utilized and healthcare expenditure, consequences of household health care expenditure, treatment cost comprising expenditures on registration/consultation, investigations (laboratory, x-ray, etc.), drugs, and other costs. Household health expenditure was computed by finding average monthly cost of outpatient care with one twelfth $(1 \div 12)$ of the cost of inpatient care. This was done since cost of outpatient care data was collected over the last four weeks preceding data collection while cost of inpatient care was for the last one year before data collection. ${ }^{[22]}$ The questionnaire was translated to Yoruba and back translated to English to ensure the original meanings were maintained.

Ethical approval to carry out the study was obtained from the Oyo State Ministry of Health Ethical Review Committee. Permission for the study was sought from the Medical Officer of Health, relevant LGA authorities and from the head of households. The household heads were informed of their right to decline or withdraw from the study at any time without any adverse consequences and informed verbal consent was obtained. Data collected was kept confidential on a password protected computer. There were no identifiers in the data collection instrument.

\section{Data Analysis}

Data was collated and analyzed using the SPSS version 21 and Stata version 12 statistical software.Wealth index was developed using Principal Components Analysis (PCA) in Stata statistical software version 12. The input to the PCA was information on ownership of house and other key assets such as a stove, electric fan, refrigerator, air conditioner, radio, television, and generator, piped water in the household, bicycle, motor vehicle, upholstered chairs, sewing machine and washing machine. For calculation of distribution cut points, quintiles were used. Each member was assigned the wealth index score of his or her household. The quintiles were Q1= Lowest, Q2=Second, Q3= Middle, Q4= Fourth, Q5=Highest. The presence or absence of adverse coping experiences was arrived at by using 14-point scale. Any household having at least one of the adverse coping methods was categorised to have had adverse coping experiences.Chi-square analysis was used to determine the difference in the association with the dependent variables (e. g healthcare utilization and source of healthcare services, presence or absence of adverse coping mechanism and consequences following health expenditure) at different levels of the independent variables. T-test was used to compare means e.g age, income, number of household members in the two LGAs. For skewed continuous variables Man-Whitney U test was used. Level of statistical significance was set at 5\%.

Household Health Care Expenditure is defined as the out-of-pocket expenditures on drug and medicines, consultation fees, hospital bed charges, transport charges to the treatment site and other cost related to the utilization of health care services.Out-of-pocket health payments refer to the payments made by households at the point they receive health services. Typically, these include registration, doctor's consultation fees, and investigations, purchases of medication, hospital bills, insurance co-payments, and expenditure on health-related transportation ${ }^{[22]}$

\section{RESUlts}

Out of 1460 total household respondents approached in both Local Government Areas (LGAs), 1434 consented and completely answered all questions, giving a response rate of 98.2\%. Of the 1434 respondents interviewed, $714(49.8 \%)$ were in the urban LGA while $720(50.2 \%)$ were in the rural LGA.

The socio-demographic characteristics of the main respondents of the household by location is shown in Table 1. Out of the 1,434 main household respondents $753(52.5 \%)$ were females. In the urban area $515(72.1 \%)$ were female respondents compared to $238(33.1 \%)$ in the rural area $(P<0.001)$. In terms of level of education in both rural and urban areas, most $(53.4 \%)$ of the main respondents had secondary level of education. In urban areas, $60.6 \%$ had secondary level of education compared to $46.3 \%$ in rural area $(P<0.001)$. 
Consequences of Health Expenditure among Rural and Urban Households in Oyo State, Nigeria

Table1. Socio-Demographic Characteristics of the Main Respondents of the Household by Location

\begin{tabular}{|c|c|c|c|c|c|}
\hline & \multicolumn{5}{|l|}{ Location } \\
\hline Variables & $\begin{array}{l}\text { Urban } \\
(\mathrm{N}=714) \mathrm{n}(\%)\end{array}$ & $\begin{array}{l}\text { Rural } \\
(\mathrm{N}=720) \mathbf{n}(\%)\end{array}$ & $\begin{array}{l}\text { Total } \\
(\mathrm{N}=1434) \mathrm{n}(\%)\end{array}$ & $\begin{array}{l}\text { Test } \\
\text { statistics }\end{array}$ & P-Value \\
\hline \multicolumn{6}{|c|}{ Sex of the household respondent } \\
\hline Male & 199(27.9) & $482(66.9)$ & $681(47.5)$ & $\chi^{2}$ & $<0.001$ \\
\hline Female & $515(72.1)$ & $238(33.1)$ & $753(52.5)$ & 219.481 & \\
\hline \multicolumn{6}{|c|}{ Age of household respondents in years } \\
\hline$<30$ & $278(38.9)$ & $336(46.7)$ & $614(42.8)$ & $\chi^{2}$ & $<0.001$ \\
\hline $30-39$ & $286(40.1)$ & 141(19.6) & $427(29.8)$ & 76.702 & \\
\hline$\geq 40$ & $150(21.0)$ & 243(33.8) & $393(27.4)$ & & \\
\hline \multicolumn{6}{|c|}{ Highest level of Education Completed } \\
\hline No formal education & $16(2.2)$ & $100(13.9)$ & $116(8.1)$ & $\chi^{2}$ & $<0.001$ \\
\hline Primary & $77(10.8)$ & $93(12.9)$ & $170(11.9)$ & 75.46 & \\
\hline Secondary & $433(60.6)$ & $333(46.3)$ & $766(53.4)$ & & \\
\hline Tertiary & $188(26.3)$ & 194(26.9) & $382(26.6)$ & & \\
\hline \multicolumn{6}{|l|}{ Tribe } \\
\hline Yoruba & $646(90.5)$ & $674(93.6)$ & $1320(92.1)$ & $\chi^{2}$ & $<0.001$ \\
\hline Ibo & $67(9.4)$ & $24(3.3)$ & $91(6.3)$ & 40.062 & \\
\hline $\begin{array}{l}\text { Others(Urobo, } \\
\text { Idoma) }\end{array}$ & $1(0.1)$ & $22(3.1)$ & $23(1.6)$ & & \\
\hline \multicolumn{6}{|l|}{ Religion } \\
\hline Christianity & $484(67.8)$ & $338(46.9)$ & $822(57.3)$ & $\chi^{2}$ & $<0.001$ \\
\hline Islam & $228(31.9)$ & $360(50.0)$ & $599(41)$ & 72.21 & \\
\hline Traditional & $2(0.3)$ & $22(3.1)$ & $24(1.7)$ & & \\
\hline \multicolumn{6}{|l|}{ Type of family } \\
\hline Monogamous & $690(96.6)$ & $530(73.6)$ & $1220(85.1)$ & $\chi^{2}$ & $<0.001$ \\
\hline Polygamous & $24(3.4)$ & $190(26.4)$ & $214(14.9)$ & 149.727 & \\
\hline
\end{tabular}

Table 2 shows the characteristics of respondents' households by location. The overall mean number of

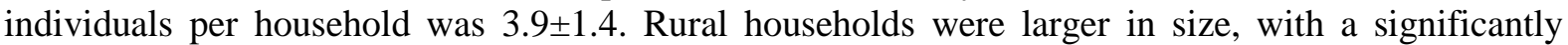
higher proportion $289(40.1 \%$ ) having five (5) or more household members as compared to $134(18.8 \%)$ of surveyed urban households. Regarding the enrolment of household members in the National Health Insurance Scheme or other health insurance $67(9.4 \%)$ of the urban households and only $2(0.3 \%)$ of the rural households had household members enrolled, $P<0.001$.

Table2. Household Characteristics in Urban and Rural Locations

\begin{tabular}{|c|c|c|c|c|c|}
\hline \multicolumn{6}{|c|}{ Location } \\
\hline Variables & $\begin{array}{l}\text { Urban } \\
(\mathrm{N}=714) \mathbf{n}(\%)\end{array}$ & $\begin{array}{l}\text { Rural } \\
(\mathrm{N}=720) \mathbf{n}(\%)\end{array}$ & $\begin{array}{l}\text { Total } \\
(\mathrm{N}=1434) \mathbf{n}(\%)\end{array}$ & $\begin{array}{l}\text { Test } \\
\text { statistics }\end{array}$ & p-value \\
\hline \multicolumn{6}{|c|}{ Number of individual all households } \\
\hline$<5$ & $580(81.2)$ & 431(59.9) & $1011(70.5)$ & $\chi^{2}$ & $<0.001$ \\
\hline$\geq 5$ & 134(18.8) & $289(40.1)$ & $423(29.5)$ & 78.732 & \\
\hline \multicolumn{6}{|c|}{ Enrolment of household members in NHIS or other health insurance scheme } \\
\hline Enrolled & $67(9.4))$ & $2(0.3)$ & $69(4.8)$ & $\chi^{2}$ & $<0.001$ \\
\hline Not enrolled & $647(90.6)$ & $718(99.7)$ & $1365(95.2)$ & 64.901 & \\
\hline \multicolumn{6}{|l|}{ Wealth quintiles } \\
\hline Lowest & $43(6.0)$ & $245(34.0)$ & $288(20.1)$ & $\chi^{2}$ & $<0.001$ \\
\hline Second & $90(12.6)$ & $185(25.7)$ & $275(19.2)$ & 340.085 & \\
\hline Middle & $165(23.1)$ & $133(18.5)$ & $298(20.8)$ & & \\
\hline Fourth & $174(24.4)$ & $121(16.8)$ & $295(20.6)$ & & \\
\hline Highest & $242(33.9)$ & $36(5.0)$ & $278(19.4)$ & & \\
\hline \multicolumn{6}{|c|}{ Monthly Household income in } \\
\hline $\begin{array}{l}\text { Median monthly } \\
\text { Household income } \\
\text { in (Range) }\end{array}$ & $\begin{array}{l}43,500 \\
(7,000- \\
680,000)\end{array}$ & $\begin{array}{l}42,000 \\
(4,000-200,000)\end{array}$ & $\begin{array}{l}42,000 \\
(4,000-680,000)\end{array}$ & $*$ & 0.651 \\
\hline
\end{tabular}

*Mann-Whitney Test

In the urban LGA $242(33.9 \%)$ were in the highest wealth quintiles while only $36(5 \%)$ were in the highest wealth quintiles in the rural area $(P<0.001)$. Considering household income, the median 
monthly household income in the urban LGA 43,500 ( $\$ 7,000-\$ 680,000$ ), was higher than $42,000$ ( $\$ 4,000-\$ 200,000)$ in the rural area. However, the difference in the median monthly income is not statistically significant $(P=0.651)$.

Health care utilization by households, and household respondents in rural and urban locations were as shown in Table 3. Health care services was utilized by 1,006 (70.2\%) of the households studied. There was a higher proportion of households in the urban area $637(89.2 \%)$ that utilized health care services compared to rural area $369(51.3 \%), P<0.001$. Information was obtained on 5,696 members in the 1,434 households surveyed. In all, 1,723 (30\%) household members utilized health care services.

Table3. Health Care Utilization and Source of Health care services by Households and Household Respondents in Rural and Urban Locations

\begin{tabular}{|c|c|c|c|c|c|}
\hline \multirow[b]{2}{*}{ Variables } & \multicolumn{5}{|l|}{ Location } \\
\hline & $\begin{array}{l}\text { Urban } \\
\text { n(\%) }\end{array}$ & $\begin{array}{l}\text { Rural } \\
\text { n(\%) }\end{array}$ & $\begin{array}{l}\text { Total } \\
\text { n(\%) }\end{array}$ & $\begin{array}{l}\text { Test } \\
\text { statistics }\end{array}$ & P-Value \\
\hline \multicolumn{6}{|l|}{$\begin{array}{l}\text { Household Utilization of } \\
\text { Health Care Services }(n=1434)\end{array}$} \\
\hline Yes & $637(89.2)$ & $369(51.3)$ & $1006(70.2)$ & $\chi^{2}$ & $<0.001$ \\
\hline No & $77(10.8)$ & $351(48.8)$ & $428(29.8)$ & 248.475 & \\
\hline \multicolumn{6}{|l|}{ 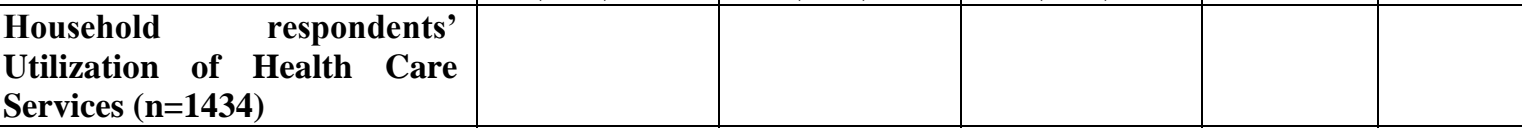 } \\
\hline Yes & $404(56.6)$ & $150(20.8)$ & 554(38.6) & $\chi^{2}$ & $<0.001$ \\
\hline No & $310(43.4)$ & $570(79.2)$ & $880(61.4)$ & 193.251 & \\
\hline \multicolumn{6}{|l|}{ Health Services } \\
\hline $\begin{array}{l}\text { Outpatient care by household } \\
\text { members }(n=5696)\end{array}$ & & & & $\chi^{2}$ & \\
\hline Yes & $744(28.7 \%)$ & $618(19.9 \%)$ & $1,362(23.9 \%)$ & 60.038 & $<0.001$ \\
\hline No & $1,848(71.3 \%)$ & $2,486(80.1 \%)$ & $4,334(76.1 \%)$ & & \\
\hline \multicolumn{6}{|l|}{ In-patient care $(n=5696)$} \\
\hline Yes & $489(18.9 \%)$ & $122(3.9 \%)$ & $611(10.7 \%)$ & 329.021 & $<0.001$ \\
\hline No & $2,103(81.1 \%)$ & $2,982(96.1 \%)$ & $5,085(89.3 \%)$ & & \\
\hline \multicolumn{6}{|l|}{$\begin{array}{l}\text { Where health services were } \\
\text { received first time }(n=1326)\end{array}$} \\
\hline Patent Medicine Store & 296(39.8) & $56(9.1)$ & $352(25.8)$ & $\chi^{2}$ & $<0.001$ \\
\hline Pharmacy & $30(4.0)$ & $41(6.6)$ & $71(5.2)$ & 353.252 & \\
\hline Health Care Providers Home & $47(6.3)$ & $4(0.6)$ & $51(3.7)$ & & \\
\hline Patient Home & $45(6.0)$ & $3(0.5)$ & $48(3.5)$ & & \\
\hline Private Hospital or Clinic & $126(16.9)$ & $59(9.5)$ & $185(13.6)$ & & \\
\hline Public Hospital & $200(26.9)$ & $455(73.6)$ & $655(48.1)$ & & \\
\hline
\end{tabular}

Regarding the utilization of both outpatient and in-patient health care by individual household members in both urban and rural locations, at the first time of receiving care $1362(23.9 \%)$ of all household members utilized out-patient health care services, out of which 744 (28.7\%) were urban dwellers and $618(19.9 \%)$ were in the rural communities, $P<0.001$. The proportion of household members in the urban area $489(18.9 \%)$ who utilized in-patient care was significantly higher than 122 $(3.9 \%)$ in the rural area, $P<0.001$.

At the first time of seeking health care services close to half 655 (48.1\%) of those who utilized health services received care at public hospital. A significantly higher proportion of these household members were from the rural area $455(73.6 \%)$ compared to 200 (26.9\%) from the urban area, $P<0.001$. Patient medicine store was utilized by 296(39.8\%) of the household members in the urban area compared to $56(9.1 \%)$ of rural household members $(P<0.001)$.

The monthly overall household health care expenditure and payment mechanism in urban and rural LGA is as shown in table 4. The median cost of health care per household in both urban and rural location was 1,377 ( $\$ 10-17,700$ ). The median monthly household cost of health care for urban household was 890 ( $\$ 10$ - 17,700 ) while the rural household had a median cost of $\$ 2,600$ ( $\$ 50$ - 
\#28,900). This difference seen in the household health care expenditure was statistically significant, $P<0.001$.

Table4. Monthly Overall Household Health Care Expenditure and payment mechanism in Urban and Rural $L G A$

\begin{tabular}{|c|c|c|c|c|c|}
\hline Variables & $\begin{array}{l}\text { Urban } \\
\mathrm{n}(\%) \\
\end{array}$ & $\begin{array}{l}\text { Rural } \\
\text { n(\%) }\end{array}$ & $\begin{array}{l}\text { Total } \\
\mathrm{n}(\%) \\
\end{array}$ & $\begin{array}{l}\text { Test } \\
\text { statistics }\end{array}$ & $\begin{array}{l}\text { P- } \\
\text { Value }\end{array}$ \\
\hline $\begin{array}{l}\text { Overall monthly household } \\
\text { health care cost in (median } \\
\text { range) }\end{array}$ & $\begin{array}{l}\$ 890 \\
(\$ 10-\$ 17,700)\end{array}$ & $\begin{array}{l}\$ 2,600 \\
(\mathrm{~N} 50- \\
¥ 28,900) \\
\end{array}$ & $\begin{array}{l}1,377 \\
(\mathrm{~N} 10- \\
\$ 17,700)\end{array}$ & $*$ & $<0.001$ \\
\hline \multicolumn{6}{|c|}{ Who made payment for most of the health care expenses $(n=1723)$} \\
\hline Self & $316(29.8)$ & $212(32.0)$ & $528(30.6)$ & $\chi^{2}$ & $<0.001$ \\
\hline Spouse & $234(22.1)$ & $227(34.2)$ & $461(26.8)$ & 108.304 & \\
\hline Friends & $4(0.4)$ & $2(0.3)$ & $6(0.3)$ & & \\
\hline Parents & $462(43.6)$ & $146(22.0)$ & $608(35.3)$ & & \\
\hline Others $\dagger$ & $44(4.2)$ & $76(11.5)$ & $120(7.0)$ & & \\
\hline \multicolumn{6}{|c|}{ How payment was made $(n=1573)$} \\
\hline Out of pocket paid once & $1006(96.4)$ & $501(94.7)$ & 1507(95.8) & $\chi^{2}$ & 0.179 \\
\hline $\begin{array}{l}\text { Out of pocket paid in } \\
\text { instalment }\end{array}$ & $28(2.7)$ & $21(4.0)$ & $49(3.1)$ & 4.899 & \\
\hline $\begin{array}{l}\text { Out of pocket but reimbursed } \\
\text { by employer }\end{array}$ & $5(0.5)$ & $1(0.2)$ & $6(0.4)$ & & \\
\hline In kind & $5(0.5)$ & $6(1.1)$ & $11(0.7)$ & & \\
\hline
\end{tabular}

*Mann-Whitney U Test, Others $\dagger$ employer, teacher, boss at work

How payment was made for most health care expenses made by household members was documented for 1573 household members, 1,507 (95.8\%) of all who made payment made it out of pocket and the money was paid once, 1,006 (96.4\%) were from urban LGA while 501 (94.7\%) were from rural LGA. Payment in instalment was made by $49(3.1 \%)$ of all who paid for health care. A slightly higher proportion $21(4 \%)$ among rural residents compared with $28(2.7 \%)$ among urban residents but the difference was not statistically significant, $P=0.179$. (Table 4)

Figure 1 shows the (adverse) coping mechanism for households in rural and urban LGA. Households with at least one adverse coping mechanism were categorised as having adverse coping mechanism. A higher proportion of urban households $505(79.3 \%)$ had adverse coping mechanism due to health care cost compared to $54(14.6 \%)$ of rural households, $P<0.001$.

Figure1. Location and Presence of Adverse Consequences/Coping Mechanism among rural and urban communities in Oyo state

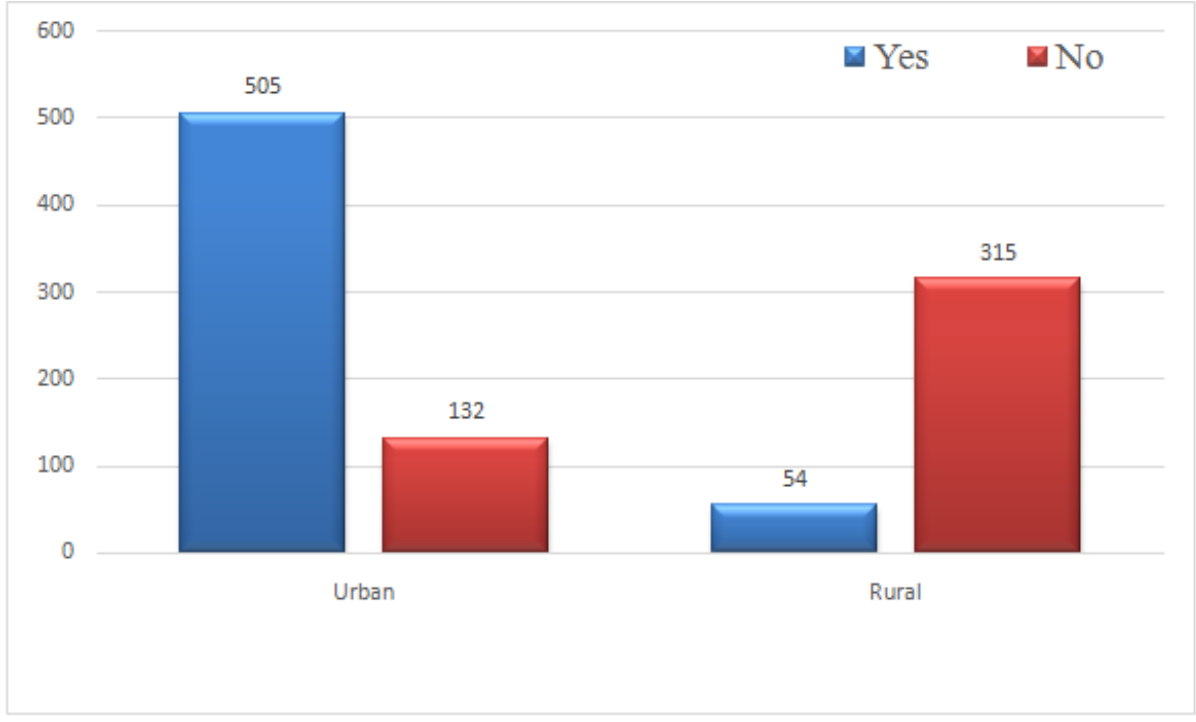

Figure1. Location and Presence of Adverse Consequences/ Coping Mechanism $X^{2}=345.46, p<0.001$ 
What the households are currently doing to cope with health care cost in both rural and urban locations are as shown in table 5. A significantly higher proportion of the households in the urban area $98(15.4 \%)$ did not seek health care compared to $6(1.6 \%)$ who had similar experiences in the rural area, $P<0.001$. Refusal to buy prescribed drugs affected $144(22.6 \%)$ of urban households compared to $5(1.4 \%)$ of rural households, $\mathrm{p}<0.001$. Reduction of meals or food intake affected $86(13.5 \%)$ households in the urban LGA compared to $28(7.6 \%)$ in rural households.

Table5. Households Current Coping Strategies in both Rural and Urban Locations

\begin{tabular}{|c|c|c|c|c|c|}
\hline Variables & $\begin{array}{l}\text { Urban } \\
(\mathrm{N}=637) \\
\mathrm{n}(\%)\end{array}$ & $\begin{array}{l}\text { Rural } \\
(\mathrm{N}=369) \\
n(\%)\end{array}$ & $\begin{array}{l}\text { Total } \\
(\mathrm{N}=1006) \\
\mathrm{n}(\%)\end{array}$ & $\begin{array}{l}\text { Test } \\
\text { statistics }\end{array}$ & $\begin{array}{l}\text { P- } \\
\text { Value }\end{array}$ \\
\hline \multicolumn{6}{|c|}{ Health Care Services not sought } \\
\hline Yes & $98(15.4)$ & $6(1.6)$ & $104(10.3)$ & & $<0.001$ \\
\hline No & $539(84.6)$ & $363(98.4)$ & $902(89.7)$ & 47.717 & \\
\hline \multicolumn{6}{|c|}{ Inability to buy prescribed drugs } \\
\hline Yes & $144(22.6)$ & $5(1.4)$ & 149(14.8) & & $<0.001$ \\
\hline No & 493(77.4) & 364(98.6) & $857(85.2)$ & 83.628 & \\
\hline \multicolumn{6}{|c|}{ Reduction of meals or food in-take } \\
\hline Yes & $86(13.5)$ & $28(7.6)$ & 114(11.3) & & $<0.004$ \\
\hline No & $551(86.5)$ & $341(92.4)$ & $892(88.7)$ & 8.130 & \\
\hline \multicolumn{6}{|c|}{ Reduction of other household items } \\
\hline Yes & $28(4.4)$ & $24(6.5)$ & $52(5.2)$ & & 0.146 \\
\hline No & $609(95.6)$ & $345(93.5)$ & $954(94.8)$ & 2.119 & \\
\hline \multicolumn{6}{|c|}{ Borrowing from friends } \\
\hline Yes & $53(8.3)$ & $2(0.5)$ & $55(5.5)$ & & $<0.001$ \\
\hline No & 584(91.7) & $367(99.5)$ & $951(94.5)$ & 27.352 & \\
\hline \multicolumn{6}{|c|}{ Borrowing in Cash or Kind } \\
\hline Yes & $8(1.3)$ & $1(0.3)$ & $9(0.9)$ & \multirow[t]{2}{*}{$*$} & 0.167 \\
\hline No & $629(98.7)$ & 368(99.7) & $997(99.1)$ & & \\
\hline \multicolumn{6}{|c|}{ Seeking monetary help from religious or Charitable Organizations } \\
\hline Yes & $8(1.3)$ & $0(0.0)$ & $8(0.8)$ & & 0.031 \\
\hline No & $629(98.7)$ & $369(100)$ & $998(99.2)$ & 4.671 & \\
\hline \multicolumn{6}{|c|}{ Selling assets } \\
\hline Yes & $8(1.3)$ & $1(0.3)$ & $9(0.9)$ & & 0.110 \\
\hline No & $629(98.7)$ & $368(99.7)$ & 997(99.1) & 2.556 & \\
\hline
\end{tabular}

*Fisher's Exact Test

\section{DISCUSSION}

This study estimated and compared household healthcare expenditure and its consequences among rural and urban communities in Oyo state.Regarding the enrolment in the National Health Insurance Scheme or other health insurance only $4.8 \%$ of households interviewed were enrolled. This is similar to previous documentation that National Health Insurance Scheme (NHIS) only covers federal government employees and the coverage level is less than $5 \%$ of the general population. ${ }^{[24]}$ Health insurance was rarely used, low national coverage is responsible for this. This is similar to a study done in south East Nigeria. ${ }^{[25]}$

Health care services was utilized by 1,006 (70.2\%) of the households studied. More households in the urban area utilized health care services when compared to rural areas, this is similar to findings in the South Eastern part of Nigeria. ${ }^{[25]}$ It should not be concluded that the need for health care services is more in the urban area. Ezeoke et al. opined that where healthcare payments are made mostly through OOP spending, as found in this study, many households face the risk of not accessing care at all when ill or seeking care from low-level providers, where the quality of care is often low. ${ }^{[25]}$

Many of the household members in all the communities sought treatment from public hospital or clinic, with the frequency being highest in the rural communities. The lower cost of care at the public health facilities could have accounted for this. It was also surprising that informal providers, such as Patent Medicine Vendors were patronized more by urban dwellers despite the presence of public and 
private hospitals. This is at variance with findings by Ezeoke et al. that more rural residents received care from the Patent Medicine Vendors in South East Nigeria. ${ }^{[25]}$ However, the implication is that urban dwellers are likely to be exposed to possibly low-quality but cheaper services despite the availability of various government health care facilities, where better care could have been received.

The median monthly household cost of health care is higher for rural households. This is similar to another study in Nigeria that have also showed that the rural dwellers incur higher healthcare costs. ${ }^{[2]}$ In Kenya, urban households were found to have spent significantly more than those households in the rural areas, with the poorest households in different settings incurring the highest cost burdens. ${ }^{[1]}$

More households in the urban LGA had adverse coping mechanisms. In rural China and Lebanon an enormous burden on underprivileged households have been reported. ${ }^{[27,28]}$ A higher proportion of the households in the urban area have ever borrowed money, from friends, and neighbours to pay household health care bill compared to those who had similar experiences in the rural area. Borrowing in cash or kind to pay health care bill was done by $6.9 \%$ of urban households compared to $3.0 \%$ of rural households. Seeking monetary help from religious or Charitable Organizations to pay for Health care was also done by 78(12.2\%) households in the urban LGA compared to 6(1.6\%) in rural households. Opportunity for borrowing and seeking monetary help seems to be more in the urban area. This further hinder the chances of the rural communities from seeking health care. Selling of household assets occurred in both urban and rural households. In Burkina Faso, the sale of assets and livestock as a way of coping with payment for common illnesses such as malaria has been reported. ${ }^{[29]}$

A significantly higher proportion of the households in the urban area 98(15.4\%) did not seek health care compared to 6(1.6\%) in the rural area. Households not seeking care in an attempt not to incur cost, led many households to incur greater costs on the long run because of repeated visit and possible complications from illnesses that could have been abated if care were sought earlier. Inability to buy prescribed drugs affected 144(22.6\%) of urban households compared to 5(1.4\%) of rural households. Reduction of meals or food intake affected 86(13.5\%) household in the urban LGA compared to $28(7.6 \%)$ in rural households. Currently borrowing from friends was the case in 53(8.3\%) of the households in urban area compared to $2(0.5 \%)$ in rural area. This has the potential of descending the households into further poverty. Debt for health care have robust associations with poverty creation and the interaction of these factors is very significantly implicated with the analysis of households' descent into poverty in India. ${ }^{[30]}$ Some households may be in debt or poverty for a long period of time after the illness that created the debt similar to findings in Ghana. ${ }^{[31]}$ In Cambodia as a mitigating strategy to coping for the financial shock of health expenditure, several household depleted their monthly general income, past saving; borrowing with/without interest, some sold the property and these contributed to impoverishment to the household economics. ${ }^{[32]}$ Sale of assets, borrowing, and reduction in household consumption, which are all likely to have adverse effects on household wellbeing have been documented..$^{[33]}$

\subsection{Limitations of the Study}

A potential bias in this study was recall. This might have been present as is usual in self -reported prevalence surveys. Recall bias was reduced by limiting enquiries on out-patient care to one month and admission services to one year. These cut-offs have been used widely in several countries. ${ }^{[31]}$

In addition, income earned especially in rural area were likely to have been overestimated. Analysis was therefore not based on only income. Presence of household assets were used to derive wealth quintiles. Estimates of health expenditure did not capture individuals who did not seek care due to various barriers. Failing to capture the poorest of the poor could lead to underestimation of the incidence and intensity of catastrophic payments and impoverishment. The poorest may avoid utilizing health care services thereby giving a false reduction of the incidence of health care utilization. This study was also only limited to direct cost of care and indirect cost of illnesses were not captured.

\subsection{Interpretation and Implication}

More households in the urban area had adverse coping mechanisms due to health care cost compared to rural households. Protection of interest of all vulnerable people in both rural and urban LGA should 
be addressed in policy formulations to ensure better access and high degree of financial protection against the impact of health care expenditure.

\section{REFERENCES}

[1] Leive A, Xu K. Coping with out-of-pocket health payments: empirical evidence from 15 African countries. Bull World Health Organ. 2008; 86:817-908.

[2] Onwujekwe O, Okereke E, Onoka C, Uzochukwu B, Kirigia J, Petu A. Willingness to pay for communitybased health insurance in Nigeria: do economic status and place of residence matter? . Health Policy and Planning 2009; 25(2):155-61.

[3] Wiesmann D, Jütting J. The emerging movement of community based health insurance in Sub-Saharan Africa: experiences and lessons learned. Afrika Spectrum. 2000; 35(2):193-210.

[4] Onwujekwe O, Hanson K, Uzochukwu B, Ichoku H, Ike E, Onwughalu B. Are malaria treatment expenditures catastrophic to different socio-economic and geographic groups and how do they cope with payment? A study in southeast Nigeria. Tropical Medicine and International Health. 2010; 15(1):18-25.

[5] Ataguba JE. Reassessing Catastrophic Health-Care Payments with a Nigerian Case Study. Health Economics, Policy and Law. 2011. http://ssrn.com/abstract=1803048

[6] Xu K, Evans DB, Kawabata K, Zeramdini R, Klavus J, Murray CJ L. Household catastrophic health expenditure: a multi-country analysis. Lancet. 2003; 362:111-7.

[7] Castillo-Riquelme M, McIntyre D, Barnes K. Household burden of malaria in South Africa and Mozambique: is there a catastrophic impact. Tropical Medicine and International Health. 2008; 13:108-22.

[8] Water HR, Anderson GF, Mays J. Measuring financial protection in health in the United States. Health Policy. 2004; 69:339-49.

[9] Ranson MK. Reduction of catastrophic health care expenditures by a community-based health insurance scheme in Gujarat, India: current experiences and challenges. Bull World Health Organ. 2002; 80:613-21.

[10] Asenso-Okyere W, Anum A, Osei-Akoto I, Adukonu A. Cost recovery in Ghana: are there any changes in health care seeking behaviour? Health Policy Plan. 1998; 13:181-8.

[11] Chuma J, Gilson L, Molyneux K. Treatment seeking behavior, cost burdens and coping strategies among rural and urban households in coastal Kenya: an equity analysis. Trop Med Int Health. 2007; 12:673-86.

[12] Ranson MK. Reduction of catastrophic healthcare expenditures by a community-based health insurance scheme in Gujarat, India: current experiences and challenges. Bulletin of the World Health Organization. 2002; 80:613-21.

[13] Russell S. The economic burden of illness for households in developing countries: a review of studies focusing on malaria, tuberculosis, and human acquired immunodeficiency syndrome. Am J Trop Med Hyg 2004; 71 (Suppl 2):147-55.

[14] Kruk M, Goldmann E, Galea S. Borrowing and paying to pay for care in low and middle income countries. Health Aff. 2009; 28:1056 - 66.

[15] Ilesanmi, O. S., Adebiyi, A., \& Fatiregun, A. A. National Health Insurance Scheme: How Protected Are Households in Oyo State, Nigeria from Catastrophic Health Expenditure? International Journal of Health Policy and Management, 2014 2(4), 175-180. doi:10.15171/ijhpm.2014.39

[16] Hay SI, Guerra CA, Tatem AJ, Atkinson PM, Snow RW. Urbanization, malaria transmission and disease burden in Africa. Nat Rev Microbiol. 2005 January; 3(1):81-90.

[17] Oyedeji OA, Oluwayemi IO, Afolabi AA, O. B, FaderoF.F. Severe Malaria at a Tertiary Paediatric Emergency Unit in South West Nigeria. Research Journal of Medical Sciences. 2010; 4(6):352-6.

[18] Uzochukwu B, Sibeudu F, Onwujekwe O, Ezeoke O, Emma-Ukaegbu U. Malaria treatment services in Nigeria: A review. Niger Med J 2010;51:1149.http://www.nigeriamedj.com/article.asp?issn=03001652 ; year $=2010 ;$ volume $=51$; issue $=3$; spage $=114 ;$ epage $=119$; aulast $=$ Uzochukwu

[19] Oyo State Government. Ibadan South west local Government 2011 [accessed 24 May, 2011]. Available from: http://www.oyostate.gov.ng/government/Ibadan-south-west

[20] National Population Commission. Final results of 2006 Population Census of the Federal Republic of Nigeria. Abuja. 2006

[21] Kirkwood B R, editor. Essentials of Medical Statistics. 2nd ed: Blackwell Science Ltd.

[22] O’Donnell O, van Doorslaer E, Wagstaff A, Lindelow M. Analyzing health equity using household survey data: A guide to techniques and their implementation. Washington, D.C: The World Bank; 2008.

[23] Margaret Grosh, Paul Glewwe. Designing Household Survey Questionnaires for Developing Countries Lessons from 15 years of the Living Standards Measurement Study2000 [cited 2011 25th May] 
[24] NHIS. Road map for the implementation of Community-based health insurance scheme in Nigeria. Consultation on Support to NHIS CBSHIS roll-out in Programme States. Abuja: PPRINN-MNCH/NHIS, 2011.

[25] Ezeoke OP, Onwujekwe OE, Uzochukwu BS. Towards Universal Coverage: Examining Costs of Illness, Payment, and Coping Strategies to Different Population Groups in Southeast Nigeria. The American Journal of Tropical Medicine and Hygiene. 2012;86(1):527.http://www.ajtmh.org/con tent/86/1/52.abstract

[26] Onwujekwe O, Uzochukwu B. Socio-economic and geographic differentials in costs and payment strategies for primary health care services in Southeast Nigeria. Health Policy and Planning. 2005; 71:383 - 97.

[27] Sun X, Jackson S, Carmichael G, Sleigh AC. Catastrophic medical payment and financial protection in rural China: evidence from the New Cooperative Medical Scheme in Shandong Province. Health Economics. 2009; 18:103-19.

[28] Salti N, Chaaban J, Raad F. Health equity in Lebanon: a microeconomic analysis. Int J Equity Health. 2010; 9(11).

[29] Sauerborne Nougtara A, Hien M, Diesfield J Seasonal variations of household costs of illness in Burkina Faso Social science \& medicine (1982). 1996;43:281 - 90.

[30] Krishna A. Pathways Out of and Into Poverty in 36 Villages of Andhra Pradesh. India World Development. 2006; 34(2):271-88.

[31] Mock C, Gloyd S , Adjei S, Acheampong F , Gish O. Economic costs of injury and resulting family coping strategies in Ghana. Accid Anal Prev. 2001; 819: 1 - 10.

[32] Damme V W, Leemput L V, Por I, Hardeman W, Meessen B. Out-of-pocket health expenditure and debt in poor households: evidence from Combodia. Tropical Medicine and International Health. 2004; 9:27380.

[33] Van Doorslaer E, O'Donnell O, Rannan-Eliya R, Somanathan A, Adhikari S, Garg C, et al. Effect of payments for health care on poverty estimates in 11 countries in Asia: an analysis of household survey data. Lancet. 2006; 368:1357-64.

Citation: Olayinka Stephen Ilesanmi, et.al. "Consequences of Health Expenditure among Rural and Urban Households in Oyo State, Nigeria" International Journal of Managerial Studies and Research (IJMSR), vol 8, no. 9, 2020, pp. 8-17. doi: https://doi.org/10.20431/2349-0349.0809002.

Copyright: (c) 2020 Authors. This is an open-access article distributed under the terms of the Creative Commons Attribution License, which permits unrestricted use, distribution, and reproduction in any medium, provided the original author and source are credited. 